\title{
Attitudes toward fertility and fertility preservation in women with glioma
}

\section{Rachel K. Stiner ${ }^{\circ}$, Jennifer L. Clarke, Nikita Sinha, Jessica Chan, Joseph M. Letourneau, Erin E. Niemasik, Jane E. Rabbitt, Susan M. Chang, Nicholas A. Butowski, Michael D. Prados, and Mitchell P. Rosen}

\begin{abstract}
Department of Neurological Surgery, University of California, San Francisco, USA (R.K.S., J.L.C., J.E.R., S.M.C., N.A.B., M.D.P.); Department of Obstetrics, Gynecology and Reproductive Sciences, University of California, San Francisco, USA (N.S., J.M.L., M.P.R.); Department of Obstetrics and Gynecology, Cedars Sinai Medical Center, Los Angeles, CA, USA (J.C.); Department of Obstetrics and Gynecology, Kaiser Permanente, San Francisco, CA, USA (E.E.N.).
\end{abstract}

Corresponding Author: Rachel Stiner, MS, School of Medicine, University of California, 1001 Health Sciences Rd, Irvine, CA 92617 (stinerr@uci.edu).

\begin{abstract}
Background. No studies have examined the fertility priorities of women undergoing treatment for their glioma. Glioma patients frequently undergo chemotherapy as part of their treatment; however, it is unknown whether patients truly are aware of its possible effects on their fertility. Our objective was to assess the fertility priorities of glioma patients and ascertain whether female glioma patients are being effectively counseled on the effects of chemotherapy on their fertility prior to beginning treatment.

Methods. The sample was composed of female patients from the Neuro-oncology clinic of the University of California, San Francisco. Participants completed a cross-sectional survey between October 2010 and December 2013 exploring their attitudes toward fertility and their experience with fertility counseling prior to chemotherapy initiation.

Results. Seventy-two women completed the survey. Analysis of the survey results showed that $30 \%$ of women receiving chemotherapy reported having a discussion regarding fertility preservation prior to beginning treatment. Of those who reported having this discussion, $80 \%$ were aware that chemotherapy could negatively affect their fertility. Many women reported that while fertility preservation was not important to them at the time of diagnosis, it was a priority for them at the time of survey completion. Although interest in having children tended to decrease after cancer treatment, the majority of respondents reported wanting a child after treatment.

Conclusions. The data obtained in this study suggest a lack of understanding of reproductive priorities, which may be addressed with a more comprehensive fertility discussion prior to beginning treatment.
\end{abstract}

\section{Keywords}

brain cancer | glioma | fertility | fertility preservation

Approximately 19000 gliomas will be diagnosed in the United States in 2018, of which more than half will be glioblastoma. ${ }^{1}$ Approximately $40 \%$ of gliomas occur in females, and about $14 \%$ of those are diagnosed in women of childbearing potential (defined as age 15-39). Prognosis for patients with glioma depends on tumor grade and molecular characteristics; those with grade II gliomas have a median survival of approximately 13 years. ${ }^{2}$ Patients with glioblastoma (grade IV astrocytoma), in contrast, have a median survival of only approximately 15-20 months, ${ }^{3,4}$ with approximately $10 \%$ surviving 5 years or longer. ${ }^{1,5}$ Prognosis is better in younger patients, and periods of disease control off-treatment can be achieved, which means that fertility after treatment is a relevant concern for many of these patients, male or female. At present no studies have evaluated the impact of treatment on fertility for patients with brain tumors, despite the loss of reproductive ability being recognized as a significant side effect of many cancer 
therapies. ${ }^{6,7}$ Chemotherapy and/or radiation are essential components of cancer treatment and can be directly gonadotoxic and/or affect the hypothalamic/pituitary hormonal axis. For women, the damage may be severe and result in either complete sterility (ovarian failure), or partial injury resulting in early menopause and infertility (inability to conceive within 12 months). ${ }^{8}$ For instance, patients who received cancer treatment during childhood were found to have higher overall incidence of acute ovarian failure, premature menopause, and adverse pregnancy outcomes later in life. ${ }^{9-11}$ Some studies report that up to half of women experience menstrual cessation with cancer treatment. ${ }^{12,13}$ While normal menses resume in some women after treatment, even the resumption of normal menses does not guarantee fertility, as studies have found that up to $40 \%$ of women whose menstrual cycle resumed after cytotoxic treatment remained infertile. ${ }^{13,14}$ As survival with cancer in reproductive-aged patients has improved, the medical community has increasingly taken an interest in patients' survivorship, in particular paying attention to treatmentrelated infertility. Multiple studies have shown that most young cancer survivors desire future childbearing, that many perceive themselves to be less fertile than their peer groups, and that infertility negatively affects survivors' quality of life.,15-17 In some patients, the desire to retain fertility was strong enough to affect their decision regarding cancer treatment. A recent study on breast cancer survivors showed that at least half of the patients reported inadequate pretreatment counseling with regard to the effects of treatment on fertility, and only $17 \%$ of the patients had a consultation with a fertility specialist. ${ }^{18}$ To date, no studies of this type have been carried out in patients with gliomas.

\section{Materials and Methods}

\section{Study Objectives and Survey Design}

This study sought to understand the incidence of decreased ovarian function in brain cancer patients, to assess the psychological impact of brain cancer and its related therapies on life aspirations including fertility-related aspirations, to evaluate the impact of reproductive function on quality of life, to assess the prevalence of patient education and physician counseling of these patients, and finally, to understand barriers to counseling in this patient population. We used a survey instrument created at University of California, San Francisco (UCSF) to examine life priorities, reproductive satisfaction, and fertility counseling in patients diagnosed with gliomas (Fig. 1). Questions were assessed for readability and validity by 2 independent experts in survey methodology. The survey was piloted on 20 patients from the UCSF Center for Reproductive Health for content and readability prior to initiation of this study. This study was cross-sectional in nature; women completed the survey at different time points after their diagnosis and during their treatment. Institutional review board approval was obtained for all elements of this study.

To analyze the effect of chemotherapy on patient fertility, we used a targeted set of questions that investigated whether patients had attempted to have a child after completing cancer treatment and if they had successfully conceived. Patients were also asked whether fertility treatment was used and if so, which methods were utilized. Additionally, patients were asked to report changes in their menstrual cycle that occurred since cancer treatment had begun.

Several survey questions were designed to understand the circumstances surrounding pretreatment fertility-preservation discussions. These questions aimed to address whether patients had a discussion regarding fertility preservation prior to treatment and, if so, who initiated the discussion, which parties participated, and with whom they would have felt most comfortable discussing the topic. Lastly, patients reported whether they were aware that chemotherapy could affect their fertility.

To better understand the priorities of women with glioma in relation to family planning and childbearing, participants were asked to rank the following categories in order of importance both before their diagnosis and after their treatment: having a child, spending time with loved ones, career, hobbies, health, and service. Women were asked to give a priority of 1 (most important) to 6 (least important), and they were able to assign the same score to 2 or more categories. Since patients completed the survey only once, and only after their treatment was initiated, they were asked to recall their priorities prior to diagnosis to the best of their abilities.

Participants were also asked to rank a series of statements relating to being pregnant and having a child based on how desirable they were. Women gave a rank of 0 (not desirable) to 10 (most desirable thing imaginable) for 18 such statements. Similarly, women were asked to rank the undesirability of 17 statements relating to aspects of pregnancy and motherhood. Participants ranked statements from 0 (desirable) to 10 (most undesirable thing

\begin{tabular}{|l|}
\hline Patient demographics \\
\hline Effect of chemotherapy on patient fertility \\
\hline Characteristics of pre-treatment fertility preservation discussion \\
\hline Patient priorities regarding family planning and childbearing \\
\hline Patient rankings of desirability and undesirability in relation to childbearing \\
\hline
\end{tabular}

Fig. 1 Fertility Questionnaire Subsections 
imaginable). Rankings for both categories (desirable and undesirable) were independent of 1 another and the same score could be assigned to multiple statements.

Finally, women were asked to indicate how strongly they agreed or disagreed with 6 statements regarding feelings toward having a child. Rankings were given on a scale of 0 (strongly disagree) to 10 (strongly agree).

\section{Study Population and Eligibility}

Eligible patients were women between the ages of 18 and 45 at the time of diagnosis who had a primary brain malignancy that was World Health Organization (WHO) grade II, III, or IV. Tumor grade was self-reported, and in analyses that consider tumor grade, participants reporting a grade of "other" were not included. Potentially eligible women were identified at check-in prior to a routine visit at the UCSF Neuro-oncology clinic. There were 4 providers seeing patients in the neuro-oncology clinic at the time the survey was taken. Interested patients were consented in clinic and were then given a link to the online survey. Patients chose to complete the survey electronically either in the office after their clinic visit or at home. If participants had not completed the survey prior to returning for a second visit, they were reminded to do so. A final reminder was given at the third visit if the participant had failed to complete the survey. Surveys were completed between 2010 and 2013.

\section{Statistical Analysis}

Survey results were analyzed using STATA Software version 10.0. Descriptive statistics including age at diagnosis, tumor grade, and parity were generated. Interest in having children before diagnosis and after treatment was compared using a chi-squared test. Data regarding fertility discussions were tabulated and described. A chi-squared test was performed to test the correlation between tumor grade and awareness that treatment affected fertility.

Priorities regarding childbearing were analyzed by averaging scores for each category and determining the difference in score before diagnosis and after treatment. $T$ tests were performed for each category. Rankings of desirability and undesirability were evaluated qualitatively to understand general desires and concerns of women regarding childbearing.

\section{Results}

\section{Study Population Demographics}

Between 2010 and 2013, 103 women were approached to participate in the survey. Of those, 99 women consented and 4 declined to participate. Of the 99 patients who consented, 72 women between the ages of 19 and 45 completed the survey. The participant characteristics are presented in Table 1. The average age of the women completing the survey was $35.3 \pm 7.06$ years old. Among the study population, $77.8 \%$ identified as white, $6.9 \%$ as Hispanic, $5.6 \%$ as Asian, $1.4 \%$ as African American, and
Table 1 Sociodemographic Characteristics of Sample at Time of Survey Completion $(n=72)^{\text {a }}$

\begin{tabular}{lc} 
Characteristic & Mean (SD) or n (\%) \\
\hline Age (years) & $35.3(7.06)$ \\
\hline Ethnicity & \\
White, Non-Hispanic & $56(77.8 \%)$ \\
Hispanic/Latino & $5(6.9 \%)$ \\
African American/Black & $1(1.4 \%)$ \\
Asian & $4(5.6 \%)$ \\
Other & $6(8.3 \%)$
\end{tabular}

Relationship status

Single $18(25.4 \%)$

Significantly involved but not living $6(8.5 \%)$ with partner

Living with partner but not married $\quad 10(14.1 \%)$

Married $34(47.9 \%)$

Separated $3(4.2 \%)$

Tumor grade

\begin{tabular}{lc}
\hline 2 & $35(48.6 \%)$ \\
\hline 3 & $24(33.3 \%)$ \\
\hline 4 & $11(15.3 \%)$ \\
\hline Other & $2(2.8 \%)$ \\
\hline Nulliparous & \\
\hline Primiparous & $41(56.9 \%)$ \\
\hline Multiparous & $13(18.1 \%)$ \\
\hline Number of children & $18(25 \%)$ \\
Cancer treatments received & $0.82(1.17)$ \\
\hline Surgery & $64(88.9 \%)$ \\
Chemotherapy & $54(75 \%)$ \\
Radiation & $41(56.9 \%)$ \\
\hline All of the above plus others & $9(12.5 \%)$ \\
\hline No treatment & $1(1.4 \%)$ \\
\hline aSeventy-two individuals completed the survey. &
\end{tabular}

8.3\% identified as either "more than one race" or "other." One person declined to state her race. The majority of women taking the survey were in some type of relationship at the time of the survey, either married (47.9\%), living with their partner but not married $(14.1 \%)$ or significantly involved but not living with their partner (8.5\%).

Grade II gliomas were the most prevalent, representing $48.6 \%$ of those surveyed. Grade III gliomas were the second most common, accounting for $33.3 \%$, followed by grade IV gliomas (glioblastoma) representing $15.3 \%$ of the sample. At the time of the survey, the vast majority $(88.9 \%)$ of participants reported receiving surgery beyond a diagnostic biopsy for their tumor, while $75 \%$ received chemotherapy, $56.9 \%$ received radiation, and $12.5 \%$ received all of the treatments listed plus others.

Participants were asked to report the number of children that they had at the time of taking the survey, and the majority of participants $(56.9 \%)$ reported being nulliparous. 
Determination of Prevalence and Effectiveness of Fertility Counseling

A central goal of the study was to assess whether fertility counseling was made available to patients prior to their initiation of any cancer treatments, and to identify any obstacles preventing this discussion. Participants were asked whether they discussed fertility preservation prior to beginning treatment, and $30 \%$ reported that they had. Approximately $61 \%$ reported not having a fertility preservation discussion, and 9\% did not remember whether they had discussed it. There was no difference in the counseling rate of those who underwent chemotherapy vs those who did not $(P=.108)$.

Patients were also asked whether they knew that cancer treatments may affect their fertility, and overall $63 \%$ reported awareness of this fact. Of those patients who had a fertility discussion, $80 \%$ were aware the treatment may impair their fertility, as opposed to only $55 \%$ of patients who did not have a fertility discussion $(P=.054)$. When evaluating by tumor type, $47 \%$ of participants with grade II tumors were aware, while $77 \%$ of those with grade III tumors and $90 \%$ of those with grade IV tumors reported awareness $(P=.01)$. After controlling for whether patients had undergone chemotherapy, this result was only borderline significant $(P=.057)$.

Several follow-up questions were asked of the 21 patients who reported having this discussion in an attempt to better understand the counseling that did occur (Table 2). The majority of patients $(52 \%)$ reported that their doctor initiated the conversation, while $33 \%$ reported that a family member brought up the issue, and $52 \%$ reported that

Table 2 Details of Fertility Discussion

\begin{tabular}{|lc|}
\hline Characteristic & Mean (SD) or $\mathrm{n}(\%)$ \\
\hline $\begin{array}{l}\text { Prior to treatments, was fertility } \\
\text { preservation discussed? }\end{array}$ & $\mathrm{n}=69$ \\
\hline Yes & $21(30.43 \%)$ \\
\hline No & $42(60.87 \%)$ \\
\hline I don't know/l don't remember & $6(8.7 \%)$ \\
\hline If yes, who brought up the discussion? & $\mathrm{n}=21$ \\
\hline Doctor & $11(52.38 \%)$ \\
\hline Family member & $7(33.33 \%)$ \\
\hline I did & $11(52.38 \%)$ \\
\hline $\begin{array}{l}\text { If yes, with whom did you have the } \\
\text { discussion? }\end{array}$ & $\mathrm{n}=21$ \\
\hline Oncologist & $17(80.95 \%)$ \\
\hline Gynecologist & $7(33.33 \%)$ \\
\hline Reproductive specialist & $6(28.57 \%)$ \\
\hline Nurse & $2(9.52 \%)$ \\
\hline Don't remember & $1(4.76 \%)$ \\
\hline Other & $1(4.76 \%)$ \\
\hline $\begin{array}{l}\text { With whom would you have felt most } \\
\text { comfortable having the discussion? }\end{array}$ & $\mathrm{n}=21$ \\
\hline Oncologist & $8(38.10 \%)$ \\
\hline Reproductive Specialist & $13(61.90 \%)$ \\
\hline
\end{tabular}

they themselves raised the discussion (options were not mutually exclusive). Patients were most likely to engage in the conversation with their oncologist, followed by their gynecologist, reproductive specialist, nurse, and social worker. Most patients who had this discussion reported that they would have felt most comfortable having the discussion with a reproductive specialist $(62 \%)$; however, a sizable group reported that they would have preferred discussing fertility preservation with their oncologist (38\%).

Participants were asked why they did not initiate a discussion with their doctor, and 38 women provided responses. Fourteen women (37\%) reported that fertility preservation was not important to them, even at the time of taking the survey, while 21 women (55\%) reported that fertility preservation was not important to them initially, when counseling would have taken place, but was important at the time of the survey. Other reported barriers were embarrassment toward initiating the conversation and concern for taking up the doctor's time with this discussion.

\section{Priorities of Women With Glioma Regarding Childbearing and Family Planning}

Women generally shifted from wanting more children before their diagnosis to being uncertain whether they wanted more children after their treatment. Before diagnosis, $54 \%$ of women reported wanting more children, and this number dropped to $35 \%$ after treatment. However, the proportion of women considering having more children after treatment increased, with $33 \%$ responding in this manner vs only $21 \%$ of participants giving this response prior to diagnosis. Women were also less likely to report that they were not interested in having children before their diagnosis $(16 \%)$ vs after treatment $(28 \%)$. Patient tumor grade was not correlated with desire to have a child either before or after diagnosis. A comparison of the answers given before diagnosis and after treatment is given in Table 3.

Participants were also asked to rank 6 categories regarding life priorities in order of importance before diagnosis and after treatment (Table 4). On average, women reported that "spending time with loved ones" was their top priority both prior to diagnosis and after receiving treatment. "Having a child" and "Career" became less important, with average changes of 0.51 points and 0.81 points, respectively, while "Health" and "Service" became more important, with average changes of 0.84 and 0.31 , respectively.

Table 3 Interest in Having More Children

\begin{tabular}{|lll|}
\hline Response & $\begin{array}{l}\text { Before Diagnosis } \\
(\mathrm{n}=71)\end{array}$ & $\begin{array}{l}\text { After Diagnosis } \\
(\mathrm{n}=40)\end{array}$ \\
\hline Yes & $38(53.5 \%)$ & $14(35 \%)$ \\
\hline No & $11(15.5 \%)$ & $11(27.5 \%)$ \\
\hline Considering & $15(21.1 \%)$ & $13(32.5 \%)$ \\
\hline Hadn't thought about it & $7(9.9 \%)$ & $2(5.0 \%)$ \\
\hline
\end{tabular}


Table 4 Average Ranking of Priorities

\begin{tabular}{|c|c|c|c|c|}
\hline Response & $\begin{array}{l}\text { Before Diagnosis }{ }^{a} \\
(n=71)\end{array}$ & $\begin{array}{l}\text { After Diagnosis } \\
(n=40)\end{array}$ & $\begin{array}{l}\text { Average } \\
\text { Difference (SD) }\end{array}$ & $\begin{array}{l}P \text { Value of } \\
T \text { Test }\end{array}$ \\
\hline Career & $2.97(1.59)$ & $3.78(1.44)$ & $-0.806(1.76)$ & 0.0003 \\
\hline Having a child & $3.78(1.86)$ & $4.31(1.78)$ & $-0.508(2.04)$ & 0.0238 \\
\hline Health & $2.86(1.38)$ & $2(1.32)$ & $0.836(1.53)$ & 0.0001 \\
\hline Hobbies & $4.17(1.17)$ & $4.17(1.14)$ & $0.049(1.16)$ & 0.7419 \\
\hline Service & $4.62(1.46)$ & $4.45(1.21)$ & $0.306(1.22)$ & 0.0265 \\
\hline Spending time with loved ones & $2.27(1.48)$ & $1.97(1.21)$ & $0.235(1.15)$ & 0.1032 \\
\hline
\end{tabular}

Table 5 Ranking of Desirability at Time of Survey Completion

\begin{tabular}{|c|c|}
\hline Characteristic & $\operatorname{Mean}^{\mathrm{a}}$ (SD) \\
\hline Having a family & $7.16(3.68)$ \\
\hline $\begin{array}{l}\text { Experiencing a close bond between myself } \\
\text { and my child }\end{array}$ & $6.99(3.61)$ \\
\hline Guiding and teaching my child & $6.99(3.55)$ \\
\hline Seeing my baby's own personality emerge & $6.64(3.71)$ \\
\hline Holding and cuddling a baby & $6.09(3.71)$ \\
\hline $\begin{array}{l}\text { Devoting myself to raising children and being } \\
\text { a mother }\end{array}$ & $5.94(3.96)$ \\
\hline Having a son or a daughter & $5.76(3.88)$ \\
\hline $\begin{array}{l}\text { Being physically connected to my baby for } \\
9 \text { months }\end{array}$ & $5.43(3.74)$ \\
\hline Being able to get pregnant & $5.34(3.89)$ \\
\hline $\begin{array}{l}\text { Giving my partner the satisfaction of being a } \\
\text { parent }\end{array}$ & $5.31(3.75)$ \\
\hline Feeling a baby move and kick inside me & $5.27(3.75)$ \\
\hline Seeing family resemblance & $5.20(3.71)$ \\
\hline Giving birth to a baby & $4.86(4.03)$ \\
\hline Having companionship through a child & $4.86(3.50)$ \\
\hline Breastfeeding a baby & $4.85(3.79)$ \\
\hline $\begin{array}{l}\text { Having a child who will carry out my family } \\
\text { tradition }\end{array}$ & $4.64(3.62)$ \\
\hline Providing my parents with grandchildren & $4.53(3.62)$ \\
\hline $\begin{array}{l}\text { Feeling more complete as a woman through } \\
\text { having a baby }\end{array}$ & $4.00(3.84)$ \\
\hline
\end{tabular}

aRanking on a scale of 1 to 10 , with lower number corresponding to lower desirability.

Participants rated 18 categories relating to having a child for desirability (Table 5). Of the 18 categories, the most highly rated was "having a family" with an average rating of 7.2, closely followed by "experiencing a close bond between myself and my child" with an average rating of 7.0. The lowest rated items were "providing my parents with grandchildren" (average rating of 4.5) and "feeling more complete as a woman through having a baby" (average rating of 4.0).

Participants also rated the "undesirability" of 17 items (Table 6). On average, the most undesirable items were
Table 6 Ranking of Undesirability at Time of Survey Completion

\begin{tabular}{ll} 
Characteristic & Mean $^{\mathrm{a}}$ (SD) \\
\hline Having a child with a genetic disease & $8.93(2.11)$ \\
\hline Having a baby who is born deformed & $8.91(2.12)$ \\
\hline $\begin{array}{l}\text { Worrying about effects of chemo/radiation on } \\
\text { embryo formation }\end{array}$ & $8.77(2.11)$ \\
\hline Becoming pregnant during a recurrence & $8.71(2.35)$ \\
\hline Leaving a child behind without a parent(s) & $8.69(2.49)$ \\
\hline Guilt of possibly leaving a child & $8.69(2.39)$ \\
\hline Passing off negative genetic traits or diseases & $8.60(2.42)$ \\
\hline Having a baby who strains my health & $7.19(2.63)$ \\
\hline Feeling guilty or inadequate as a parent & $6.45(3.29)$ \\
\hline Having a child who is a burden to my partner & $6.24(3.42)$ \\
\hline Burden on finances & $5.51(3.07)$ \\
\hline $\begin{array}{l}\text { Experiencing the pain of childbirth } \\
\text { Taking care of a sick child }\end{array}$ & $5.31(3.57)$ \\
\hline $\begin{array}{l}\text { Experiencing the discomforts of pregnancy } \\
\text { Having a baby who takes away my freedom to }\end{array}$ & $4.17(3.29)$ \\
\hline do other things & $4.43(3.48)$ \\
\hline $\begin{array}{l}\text { Being kept away from a career by a child } \\
\text { Feeling responsible for another person's life }\end{array}$ & $4.00(3.36)$ \\
\hline $\begin{array}{l}\text { Ranking on a scale of } 1 \text { to } 10, \text { with lower number corresponding to } \\
\text { lower undesirability. }\end{array}$ & \\
\hline
\end{tabular}

having a "child with a genetic disease" and "having a baby who is born deformed" with ratings of 8.93 and 8.91, respectively. The least undesirable items (eg, items that women were not as concerned about) were "feeling responsible for another person's life" and "being kept away from a career by a child" with ratings of 3.66 and 4.00 , respectively.

\section{Effect of Cancer Treatments on Fertility}

\section{Self-reported infertility}

The response rate to questions regarding patients' fertility before diagnosis and after treatment was low, with only 21 responders; 13 women (62\%) reported that they were not infertile. In addition, 4 women reported that they 
received fertility treatment prior to diagnosis, with all 4 receiving hormonal treatments, and 2 also receiving intrauterine sperm injections.

Only 4 women reported trying to conceive after completing treatment, and none of them used fertility treatment. Of these women, 1 was unable to conceive while 3 did successfully conceive.

\section{Menstrual changes}

Of the 71 women who responded to questions about the frequency of menstrual changes after treatment, $91 \%$ reported regularity in their menstrual cycles prior to treatment while $6 \%$ reported having irregular menstrual cycles and $3 \%$ did not remember.

Participants were then asked to describe how their menstrual cycle had changed since undergoing therapy. Of the 59 women who provided a response and who had begun treatment, 56\% reported some type of menstrual change since initiating cancer treatment, while $36 \%$ reported no change. The remaining $8 \%$ reported that they either did not know or their response did not fit into one of the categories defined. Of those patients who had chemotherapy, $69 \%$ reported menstrual disturbances, while only $22 \%$ of women who did not have chemotherapy (but who may have had surgery and/or radiation) reported a change. A chi-squared analysis showed that this was significant with $P=.009$.

\section{Discussion}

\section{Determination of Prevalence and Effectiveness of Fertility Counseling}

Our results are consistent with other comparable fertility studies, indicating a need for improved counseling among women undergoing chemotherapy. ${ }^{18-23}$ There are many possible reasons for lack of counseling in this population, including the potentially grave prognosis. With other cancers, studies have demonstrated that oncologists themselves feel underprepared to speak to their patients about fertility preservation, as they report not understanding recent advancements in the field. ${ }^{20,24,25}$ One study showed that the primary barrier to accessing fertility treatment was the perceived urgency of cancer treatment as conveyed by medical professionals. ${ }^{26}$ This same study showed that women were less likely than men to receive encouragement to pursue fertility preservation, perhaps reflecting the perceived simplicity of male vs female fertility preservation. Our study also found that some patients may be embarrassed about having this discussion or concerned with wasting their physicians' time, leading them to avoid broaching the topic. It would be helpful to follow up with a survey targeting neuro-oncologists, which would aid in an effort to understand the barriers to discussion from the physicians' point of view.

Interestingly, more patients reported being aware that treatments could affect their fertility than reported having a fertility discussion. This may indicate that patients are finding this information on their own using outside resources. ${ }^{27}$
The survey results also indicated that $80 \%$ of those who do report having a fertility discussion are aware that treatment may affect their fertility. This result is encouraging as it demonstrates that discussions are effective and may help patients make educated choices regarding preserving their fertility prior to treatment.

Our study is consistent with other studies reporting a low referral rate to reproductive specialists. ${ }^{22,28-30}$ While most patients in our study who had this discussion reported having it with their oncologist, patients indicated they would be most comfortable having this discussion with a reproductive specialist. In addition, about half of patients reported that they initiated a fertility preservation discussion, which is consistent with other studies showing that patients often drive a referral to a reproductive specialist. ${ }^{31}$

An interesting finding of the study was that some women reported that they did not bring up the topic of fertility preservation because it was not important to them at the time of diagnosis but was important to them at the time they were being surveyed.This discrepancy may be caused by many factors: patients being overwhelmed by the implications of their new diagnosis, not being aware that infertility is an issue, or not planning on having children at the time of diagnosis.

\section{Priorities of Women With Glioma Regarding Childbearing and Family Planning}

Results of the survey showed that women were less likely to report wanting another child after treatment than before their diagnosis. Decrease in desire for children may correspond to concerns regarding survival expectation of the mother. We were unable to correlate this change in desire with severity of diagnosis, although we postulate that this correlation may be evident given a larger sample size. In addition, women report that health becomes more important after treatment while having children loses some importance. These results show a shift of priorities toward taking care of self vs planning for a family.

In reviewing the ratings of "desirability" and "undesirability" given to topics of family planning and childbearing, a few patterns emerge. The most highly undesirable items tend to be those that pertain to either passing health problems onto offspring or leaving children without a parent. Indeed, young cancer survivors do face an increased risk of second malignancies and complications due to treatment, in addition to the risk of recurrence of their original tumor. ${ }^{32,33}$ It is clear that patients have concerns regarding the health of their future offspring, which may be addressed in a comprehensive fertility discussion. It would be helpful to conduct a follow-up study addressing the fertility and family planning concerns of men with glioma and partners of glioma patients to gain a more complete understanding of these issues.

\section{Effect of Cancer Treatments on Fertility}

While one of the goals of the study was to evaluate how cancer treatment affects the fertility of women with glioma, we were not able to answer this question with confidence because of significant nonresponse in this area of the 
survey. It is possible that women who were not attempting to have children did not respond to questions regarding fertility, even though there was an option to indicate this on the survey, or that questions may have caused emotional discomfort in some patients.

We also attempted to understand whether treatment for brain tumors had an impact on ovarian function by evaluating changes in menstrual cycle once treatment commenced. Data showed that some type of change in menstrual cycle was significantly more common among participants who underwent chemotherapy, indicating a correlation between having been treated with chemotherapy and experiencing menstrual changes. This finding is consistent with current literature evaluating similar classes of drugs. ${ }^{12,13}$ While change in menstrual cycle does not necessarily indicate loss of fertility, research has shown a correlation between women who experience menstrual changes during chemotherapy and those who report infertility. ${ }^{13}$

\section{Study Limitations}

The survey format and cross-sectional nature of the study posed several limitations to the quantity and quality of data that could be extracted. For instance, patients completed the survey after their cancer diagnosis and were asked to answer questions regarding their state of mind before their diagnosis. In particular, women were asked to recall the regularity of their menstrual cycles, their priorities regarding childbearing and family planning, and whether they had a fertility discussion. All of these data could be influenced by recall bias and by the time elapsed between the time periods in question and taking the survey, a period of time that ranged from 5 days to 14 years. There was substantial nonresponse in some areas of the survey, which prevented accurate evaluation of many of the primary questions that were raised. This nonresponse may have been due to the length of the survey, to patient discomfort toward divulsion of sensitive information, or to difficulties with patient recall. Additionally, participants were not asked to consent to a medical chart review, which prevented verification of data.

\section{Suggestions Going Forward}

Suggestions for clinicians are based on the principal results of this study, which suggest a limited knowledge from women undergoing cytotoxic chemotherapy for their brain tumor with regard to its potential impact on their reproductive health. Furthermore, the results of this survey suggest that patients who do have fertility preservation discussions with their doctors may still be left with gaps in their understanding. When feasible, we suggest that a fertility preservation discussion be initiated with a patient who is considering chemotherapy before treatment begins. It may also be helpful to have this conversation in the presence of the patient's caregiver.

Finally, it may be in the patient's best interest to offer a referral to a reproductive specialist so that patients may increase their understanding of the risks to their fertility and their options to circumvent this risk. Issues regarding health insurance coverage of consultation with a fertility expert and cost of fertility preservation procedures must be assessed on a case-by-case basis taking into account the patient's priorities and the health care available to them. Similar to the rest of oncology, survivorship for neuro-oncology patients is increasingly being recognized as a fundamental component of care, of which reproductive priorities are an important piece. As such, it is critical that neuro-oncologists address potential impacts on fertility in treatment discussions whenever possible.

\section{Funding}

None declared

Conflict of interest statement. None declared.

\section{References}

1. Ostrom QT, Gittleman H, Fulop J, et al. CBTRUS statistical report: Primary brain and central nervous system tumors diagnosed in the United States in 2008-2012. Neuro Oncol. 2015;17(Suppl 4):iv1-iv62.

2. Buckner JC, Shaw EG, Pugh SL, et al. Radiation plus procarbazine, CCNU, and vincristine in low-grade glioma. N Engl J Med. 2016;374(14):1344-1355

3. Stupp R, Mason WP, van den Bent MJ, et al; European Organisation for Research and Treatment of Cancer Brain Tumor and Radiotherapy Groups; National Cancer Institute of Canada Clinical Trials Group. Radiotherapy plus concomitant and adjuvant temozolomide for glioblastoma. N Eng/ J Med. 2005;352(10):987-996.

4. Gilbert MR, Wang M, Aldape KD, et al. Dose-dense temozolomide for newly diagnosed glioblastoma: a randomized phase III clinical trial. J Clin Oncol. 2013;31(32):4085-4091.

5. Stupp R, Hegi ME, Mason WP, et al; European Organisation for Research and Treatment of Cancer Brain Tumour and Radiation Oncology Groups; National Cancer Institute of Canada Clinical Trials Group. Effects of radiotherapy with concomitant and adjuvant temozolomide versus radiotherapy alone on survival in glioblastoma in a randomised phase III study: 5 -year analysis of the EORTC-NCIC trial. Lancet Oncol. 2009:10(5):459-466.

6. Simon B, Lee SJ, Partridge AH, Runowicz CD. Preserving fertility after cancer. CA Cancer J Clin. 2005;55(4):211-228; quiz 263-264.

7. Letourneau JM, Ebbel EE, Katz PP, et al. Pretreatment fertility counseling and fertility preservation improve quality of life in reproductive age women with cancer. Cancer. 2012;118(6):1710-1717.

8. Letourneau JM, Ebbel EE, Katz PP, et al. Acute ovarian failure underestimates age-specific reproductive impairment for young women undergoing chemotherapy for cancer. Cancer. 2012;118(7):1933-1939.

9. Signorello LB, Cohen SS, Bosetti C, et al. Female survivors of childhood cancer: preterm birth and low birth weight among their children. $J$ Natl Cancer Inst. 2006;98(20):1453-1461.

10. Sklar CA, Mertens AC, Mitby P, et al. Premature menopause in survivors of childhood cancer: a report from the Childhood Cancer Survivor Study. J Natl Cancer Inst. 2006;98(13):890-896. 
11. ChemaitillyW, Mertens AC, Mitby P, etal. Acute ovarian failure in the Childhood Cancer Survivor Study. J Clin Endocrinol Metab. 2006;91(5):1723-1728.

12. Goodwin PJ, Ennis M, Pritchard KI, Trudeau M, Hood N. Risk of menopause during the first year after breast cancer diagnosis. J Clin Oncol. 1999;17(8):2365-2370.

13. Letourneau JM, Niemasik EE, McCulloch CE, et al. Temporary amenorrhea predicts future infertility in young women treated with chemotherapy. J Cancer Res Ther. 2013;2(1):16.

14. Vassilakopoulou M, Boostandoost E, Papaxoinis G, de La Motte Rouge T, Khayat D, Psyrri A. Anticancer treatment and fertility: Effect of therapeutic modalities on reproductive system and functions. Crit Rev Oncol Hematol. 2016;97:328-334.

15. Schover LR, Rybicki LA, Martin BA, Bringelsen KA. Having children after cancer. A pilot survey of survivors' attitudes and experiences. Cancer. 1999:86(4):697-709.

16. O'Moore AM, O'Moore RR, Harrison RF, Murphy G, Carruthers ME. Psychosomatic aspects in idiopathic infertility: effects of treatment with autogenic training. J Psychosom Res. 1983;27(2):145-151.

17. Greil AL. Infertility and psychological distress: a critical review of the literature. Soc Sci Med. 1997;45(11):1679-1704.

18. Partridge AH, Gelber S, Peppercorn J, et al. Web-based survey of fertility issues in young women with breast cancer. J Clin Oncol. 2004;22(20):4174-4183.

19. Benedict C, Thom B, Friedman DN, et al. Young adult female cancer survivors' unmet information needs and reproductive concerns contribute to decisional conflict regarding posttreatment fertility preservation. Cancer. 2016;122(13):2101-2109.

20. Adams $E$, Hill $E$, Watson E. Fertility preservation in cancer survivors: a national survey of oncologists' current knowledge, practice and attitudes. Br J Cancer. 2013;108(8):1602-1615.

21. Thewes B, Meiser B, Taylor A, et al. Fertility- and menopause-related information needs of younger women with a diagnosis of early breast cancer. J Clin Oncol. 2005;23(22):5155-5165.

22. Gwede CK, Vadaparampil ST, Hoffe S, Quinn GP. The role of radiation oncologists and discussion of fertility preservation in young cancer patients. Pract Radiat Oncol. 2012;2(4):242-247.
23. Niemasik EE, Letourneau J, Dohan D, et al. Patient perceptions of reproductive health counseling at the time of cancer diagnosis: a qualitative study of female California cancer survivors. J Cancer Surviv. 2012;6(3):324-332

24. Abe A, Kuwahara A, Iwasa T, Nishimura M, Irahara M. A survey on fertility management in young women of reproductive age treated with chemotherapy. Int J Clin Oncol. 2016;21(6):1183-1190.

25. Duffy C, Allen SM, Dube C, Dickersin K. Oncologists' confidence in knowledge of fertility issues for young women with cancer. J Cancer Educ. 2012;27(2):369-376.

26. Peddie VL, Porter MA, Barbour R, et al. Factors affecting decision making about fertility preservation after cancer diagnosis: a qualitative study. BJOG. 2012;119(9):1049-1057.

27. Fox S, Sydney J. The Social Life of Health Information. Pew Research Center; 2009. http://www.pewinternet.org/2009/06/11/the-social-lifeof-health-information/. Accessed November 30, 2016.

28. Forman EJ, Anders CK, Behera MA. Pilot survey of oncologists regarding treatment-related infertility and fertility preservation in female cancer patients. J Reprod Med. 2009;54(4):203-207.

29. Forman EJ, Anders CK, Behera MA. A nationwide survey of oncologists regarding treatment-related infertility and fertility preservation in female cancer patients. Fertil Steril. 2010;94(5):1652-1656.

30. Louwé LA, ter Kuile MM, Hilders CG, et al. Oncologists' practice and attitudes regarding fertility preservation in female cancer patients: a pilot study in the Netherlands. J Psychosom Obstet Gynaecol. 2013;34(3):129-132.

31. Kim J, Deal AM, Balthazar U, et al. Fertility preservation consultation for women with cancer: are we helping patients make high-quality decisions? Reprod Biomed Online. 2013;27(1):96-103.

32. Sankila R, Pukkala E, Teppo L. Risk of subsequent malignant neoplasms among 470,000 cancer patients in Finland, 1953-1991. Int J Cancer. 1995;60(4):464-470.

33. Brierley JD, Rathmell AJ, Gospodarowicz MK, et al. Late effects of treatment for early-stage Hodgkin's disease. $\mathrm{Br} J$ Cancer. 1998;77(8):1300-1310. 